\title{
Research on the Dynamic Mechanism of National Pharmaceutical Industry Chain
}

\author{
Xiao Liping ${ }^{1, a}$, Huang Yafang ${ }^{1, b}$ \\ ${ }^{1}$ Yunnan University of Chinese Medicine, School of Humanities and Management, Kunming China
}

\begin{abstract}
This paper relies on the "China Health and Family Planning Statistical Yearbook" published by the National Bureau of Statistics. Analyzing the current development status of ethnic medicine,the driving force of the national medicine industry chain is the national medicine industry, especially the development of grassroots national medical institutions, and the core problem of solving the grassroots development is the construction of national physicians and the accelerated cultivation of national medical talents. Providing sufficient human resources to grassroots medical institutions is an important guarantee for the development of national medicine industry. Finally, on the basis of research,the development model of the national industrial chain of ethnic medicine was established.
\end{abstract}

\section{THE Question IS RAISED}

Since the 18th National Congress of the Communist Party of China,under the impetus of the state,all walks of life participate in promoting the development of Chinese medicine. As an important part of Chinese medicine, ethnic medicine has also ushered in a good time for development. In the past, ethnic medicine was used as a special medicine for some ethnic minorities. The practitioners were often regarded as folk herbalist, or the non-certificated. The "Traditional Chinese Medicine Law" implemented in 2017 is an important milestone in the development of ethnic medicine. The state has not only recognized the legal status of ethnic medicine,but also formulated special support policies for the development of ethnic medicine.

The promotion of policies has made remarkable achievements in China's national medicine industry. According to the data of China Health and Family Planning Statistical Yearbook in recent years, the development trend of ethnic medicine is good. The comparative data found that there is a trend beyond the development of Chinese medicine.Especially the nationality,the growth rate of medical hospitals in the past five years is higher than the growth of the number of Chinese medicine hospitals. This also makes the research on ethnic medicine more valuable and meaningful.

In recent years,scholars' research on ethnic medicine has focused more on protection and inheritance. The most mentioned is to protect the patent right of national medicine through legislation to protect intellectual property rights,so that the existing national medicine no longer disappears,and can be retained. Through the analysis of actual data on the development situation and development trend of the national medicine industry in recent years, it is still relatively rare to find out the problems and main driving forces of the development of the national medicine industry.

This article is based on Mongolian medicine,Tibetan medicine, Uyghur medicine and Dai medicine is the main research object. According to the data of China Health and Family Planning Statistical Yearbook for six years from 2012 to 2017, this paper compares and analyzes the overall development of the national medical undertakings and their main strengths, as well as the relationship between the development of various ethnic groups and the population. In the effort to promote the development of the Chinese medicine industry from the perspective of supply of national medicine, and to promote the national industrial chain drive model.

\section{The Overall Development of The NATIONAL MEDICINE INDUSTRY}

\subsection{The overall development of the national medical undertakings}

$B$. According to the data of China Health and Family Planning Statistical Yearbook for six years from 2012 to 2017: In the six years, the national hospitals showed an increasing trend year by year. From the number of ethnic medical hospitals, the overall growth rate of the six years was $36.54 \%$. From the perspective of medical institutions, the medical clinics were treated. The number of people in the six-year period increased by $20.39 \%$. From the number of medical institutions, the number of institutions in the national medical hospital increased by $125.79 \%$ in six years,the number of staff in the outpatient

$\overline{\mathrm{a} 42801089 @ q q . c o m,{ }^{\mathrm{b}} 1304966206 @ q q . c o m}$ 
department increased by $67.24 \%$ in six years, and the number of clinic staff increased by $29.39 \%$ in six years. Especially,it is particularly worth mentioning that the number of personnel in national hospitals and the number of people in national hospitals have risen rapidly,indicating that national hospitals play an important role in the entire medical supply system and develop rapidly. Contrary to the growth,the number of institutions in the Institute of Ethnic Medicine has dropped by $83.82 \%$. The author believes that due to the slow development of the national pharmaceutical industry,the demand for scientific research is not large. The state has always wanted to protect the national medical culture and development from the policy level. Industry,but the market demand is not yet mature, so it leads to too much institutional construction in the early stage. At present,with the development of consumption upgrading, the development of national medical undertakings will drive the development of the industry. As enterprises vigorously develop the national pharmaceutical industry, they will Increase in demand.
In summary,China's national medical undertakings have steadily increased year by year. Benefit from two aspects: On the one hand,the Chinese government has increased investment in supply,the number of ethnic hospitals,ethnic clinics and ethnic medical clinics have increased,and the number of personnel and annual outpatient clinics is also on the rise. On the other hand,the researchers believe that when the per capital GDP is higher than 8,000 dollars, consumers begin to have great demand for health. China has achieved this goal in 2015, and the health industry in recent years. To become a hot spot is proof that the health industry is not only conducive to social development, but also a new economic growth point during the economic transition period.

\subsection{Mongolian Uyghur Tibetan medicine is the main force of the national medical cause, and the development of the Dai medicine is slow,which is positively related to the population ratio.}

Table 1 Number of national medical and health institutions

\begin{tabular}{|c|c|c|c|c|c|c|}
\hline & 2012 & 2013 & 2014 & 2015 & 2016 & 2017 \\
\hline National Medical Hospital & 208 & 217 & 233 & 253 & 266 & 284 \\
\hline Mongolian Medical Hospital & 57 & 59 & 66 & 69 & 72 & 89 \\
\hline Tibetan Medicine Hospital & 42 & 41 & 40 & 41 & 45 & 45 \\
\hline Uyghur hospital & 78 & 79 & 88 & 96 & 99 & 98 \\
\hline Dai Hospital & 1 & 1 & 1 & 1 & 1 & 1 \\
\hline $\begin{array}{l}\text { Other national medical } \\
\text { hospitals }\end{array}$ & 30 & 37 & 38 & 46 & 49 & 51 \\
\hline \multicolumn{7}{|c|}{ The proportion of ethnic groups in ethnic medical hospitals: } \\
\hline Mongolian doctor & $27.40 \%$ & $27.19 \%$ & $28.33 \%$ & $27.27 \%$ & $27.07 \%$ & $31.34 \%$ \\
\hline Tibetan doctor & $20.19 \%$ & $18.89 \%$ & $17.17 \%$ & $16.21 \%$ & $16.92 \%$ & $15.85 \%$ \\
\hline Uyghur doctor & $37.50 \%$ & $36.41 \%$ & $37.77 \%$ & $37.94 \%$ & $37.22 \%$ & $34.51 \%$ \\
\hline Dai doctor & $0.48 \%$ & $0.46 \%$ & $0.43 \%$ & $0.40 \%$ & $0.38 \%$ & $0.35 \%$ \\
\hline Other ethnic doctors & $14.42 \%$ & $17.05 \%$ & $16.31 \%$ & $18.18 \%$ & $18.42 \%$ & $17.96 \%$ \\
\hline
\end{tabular}

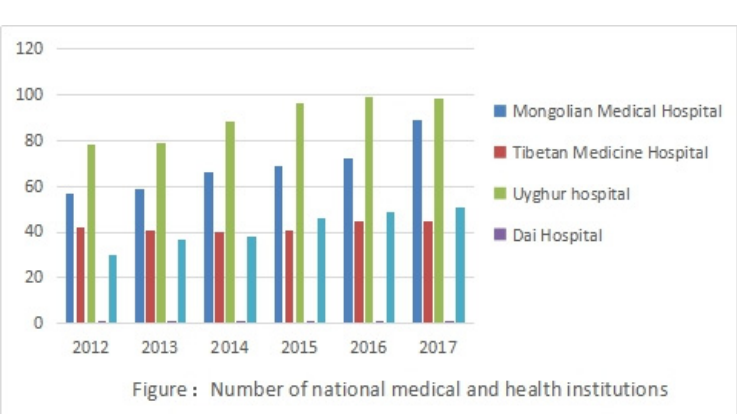

Mongolian medical hospitals, Uyghur medical hospitals and other ethnic medical hospitals have seen significant growth. The Tibetan medical hospitals have increased by three within six years. Combined with the proportional relationship in the above table. Mongolian medical hospitals and Uyghur medical hospitals has the highest proportion among the total number of ethnic medical hospitals. The number of Mongolian medical hospitals is between $27 \%$ and $31.5 \%$, that of Uyghur medical hospitals is between $34.5 \%$ and $38 \%$, and that of Tibetan medicines is about $17 \%$. The minimum number of Dai medical hospitals is less than $0.5 \%$. This phenomenon is not unrelated to the population of all ethnic groups. ${ }^{1}$ It can be seen that the more the minority population is, the more favorable it is to the development of the medical and health undertakings of the nation. The development of the national medical cause directly promotes the industrial development of the national medicine,and forms a virtuous circle,thereby promoting the development of related medicines such as scientific research,personnel training,and national medicine cultivation of ethnic medicine.

\footnotetext{
1 According to the data of the sixth national census in 2010,there are 6.5 million Mongolian people in China,about 7 million Tibetans,nearly 10.07 million Uighurs, and only 1.65 million Yi people.
} 


\subsection{The National Hospital is the main force in the development of the national medicine industry.}

Table 2 Number of personnel in national medical and health institutions

\begin{tabular}{|c|c|c|c|c|c|c|}
\hline & 2012 & 2013 & 2014 & 2015 & 2016 & 2017 \\
\hline National Medical Hospital & 14659 & 16706 & 19404 & 23156 & 26167 & 33099 \\
\hline Ethnic medical clinic & 116 & 113 & 92 & 104 & 137 & 194 \\
\hline National medical clinic & 718 & 731 & 727 & 785 & 779 & 929 \\
\hline $\begin{array}{l}\text { National Institute of Medicine } \\
\text { (Medical Sciences) }\end{array}$ & 686 & 591 & 596 & 404 & 243 & 111 \\
\hline \multicolumn{7}{|c|}{ The National Medical Hospital is a multiple of other types: } \\
\hline Outpatient department & 126.37 & 147.84 & 210.91 & $\begin{array}{r}222.6 \\
5\end{array}$ & 191.00 & 170.61 \\
\hline clinic & 20.42 & 22.85 & 26.69 & 29.50 & 33.59 & 35.63 \\
\hline graduate School & 21.37 & 28.27 & 32.56 & 57.32 & 107.68 & 298.19 \\
\hline
\end{tabular}

As can be seen from Table 2, the number of personnel accommodated in the National Hospital accounts for the vast majority of the total number of medical institutions. The development of other types of medical institutions is different. The number of personnel in the outpatient department of ethnic medicine fluctuates. More and more people are engaged in this industry, which is a good situation. While,we can clearly observe that the institutions of the National Institute of Medicine have been decreasing in recent years. The author believes that the level of professional knowledge and professional quality do not match. In simple terms, there is a high level of knowledge, and there is a lack of professional practical experience; personnel with sufficient professional and technical experience,low level of knowledge,can't do it or have no interest in related professional research. From the above table,it clearly reflects the rapid growth of the number of personnel in the national medical hospitals. Its ratio to the outpatient departments, clinics, research institutes and other national health institutions has basically increased year by year, and It is increasingly showing the trend of becoming the pillar of the development of the national medical cause. And the hospital is the only professional medical institution that can integrate medical treatment and research and development. While the development of ethnotherapy clinics and clinics at the grassroots level is slower than that of hospitals.

According to the data analysis of this paper, the statistics of medical institutions of ethnic medical undertakings include national hospitals, ethnic medical outpatient department and ethnic medical clinics.For many years, the number of personnel in the National Medical Hospital is much higher than that of the outpatient department and clinic. The primary health care service is a unit that contacts many people. The basic service capability is an important cornerstone for the national medical industry to drive the national medical industry.

\subsection{Ethnic medical care is developing rapidly compared with Chinese medicine,with huge potential.}

According to the data of China Health and Family Planning Statistical Yearbook for six years from 2012 to 2017 , both the number of medical treatments in TCM medical institutions and the total medical treatment of ethnic medical institutions are significantly increased. In the past six years, the total number of medical treatments in traditional Chinese medicine has increased by $36.36 \%$, and the number of medical treatments in ethnic medical hospitals has increased by $80.76 \%$. In addition to the slight increase in 2013, the number of medical treatments in the ethnotherapy clinics showed a downward trend. However, the surge in 2017 also brought about a huge change of $62.86 \%$ in six years. The medical career of ethnic medicines has great potential for development. The proportion of ethnic medicines in Chinese medicine has increased significantly. The diagnosis and treatment of ethnic medical clinics is basically on the rise from 2014 to 2017 , with an increase of $20.39 \%$ in the past six years. On the whole, the basic service capacity of ethnic medicines needs to be improved. From the perspective of the proportion of ethnic medicines in traditional Chinese medicine, The development momentum of hospitals is worse than that of Chinese medicine hospitals, and the development of medical treatments in ethnic medical 
clinics and ethnic outpatient clinics is not as good as Chinese medicine.

The weakness of the development of ethnic medicine is mainly due to the gradual decline in the service capacity of the grassroots. Legal national doctors often choose to work in ethnic hospitals in consideration of work preparation, stable income, scientific research and development,and the national hospitals have a small coverage and limited number of people. For example, from 2012 to 2017, there was only one Dai hospital in the hospital. From a national perspective, the development of ethnic medical clinics and ethnic clinics is not as good as that of traditional Chinese medicine. Therefore, the ability of grassroots services to be upgraded has enabled more ethnic doctors to enter the grassroots level. Public service can drive the development of the entire national pharmaceutical industry and is also a key starting point and engine for instigating the national pharmaceutical industry chain.

\section{DISCUSSION AND SUGGESTIONS}

\subsection{Enhancing the ability of national medicine grassroots service is the engine of the national pharmaceutical industry chain}

For the study of ethnic medicine, China has made outstanding achievements in the protection of intellectual property rights and literature reorganization. Then the development of the national medicine industry and the development of the industry are lagging behind,and there is a phenomenon in which the collated documents are unmanned and are in the library. With the development of urbanization,young people in rural areas have flowed into the cities. The national medicine treasures and literature scattered in the countryside have not been inherited. However,in economic considerations,rural ethnic doctors are more reluctant to contribute to the ancestral secret recipe. The number of documents rescued is extremely small. With the old generation of rural ethnic doctors,many important national medicine traditional treatments, unique ethnic medicines and precious national literature have also been lost. This is not only the loss of China but also the world loss. There are two ways to expand the scope of ethnic medicine communication: First,increase the intensity of the development of national hospitals. Compared with Chinese medicine hospitals,national hospitals develop more rapidly,so increase the number of national hospitals,improve the coverage of ethnic areas, and make bigger Strong national hospital. Second,the grass-roots institutions that formulate policies to develop ethnic medical undertakings,namely ethnic medical clinics and ethnic medical clinics, the provinces of ethnic minority agglomerations should increase the number of national doctors on the one hand, and improve the laws of practicing doctors for practicing doctors on the other hand. The resource perspective solves the supply side problem of the development of the national pharmaceutical industry.

\subsection{Improve the "Chinese Medicine Law" and seek to solve the problem of the difficulty of legal status of private doctors}

Undoubtedly, the "Traditional Chinese Medicine Law" has determined that minority medicines have the epoch-making significance as the equivalent status of Chinese medicine. National medicine was originally called folk herbalist and has no legal status. The birth of this law made the national medicine legally compliant. It enjoys the same status as traditional Chinese medicine. In addition,it is also proposed to develop ethnic medicine. For ethnic autonomous areas,the minority government has given full freedom of policy. The minority should seize the country's determination to develop ethnic medicine and the golden opportunity to vigorously promote the national medicine industry in the region. And the industry, make good use of policies and give play to policy advantages. However,in the specific development process of ethnic medicine,it is not difficult to find that the service capacity of the grassroots level is reduced. Although the "Traditional Chinese Medicine Law" stipulates that doctors who have expertise in medicine can obtain a doctor's qualification certificate by learning and assessing with the tutor,in the specific operation, the folk herbalist become legal doctors, at least 11 years,with Master. After five years of study,take the "Specialty Certificate", and then take the exam assistant practitioner's card one year later. If the assessment is not smooth,it may be more than 15 years. Taking Guangdong as an example. In 2018,there were more than 10,000 applicants, 3,600 people passed the preliminary examination,only 140 people passed the final trial,and only 92 people were admitted to the specialization certificate. The difficulty has given many illegal organizations the opportunity to illegally defraud the private doctors who are difficult to survive. And the "specialization certificate" can only see the specialist disease, if you go beyond the scope, you must take the full-time professional doctor's card,and then spend your energy to register for a one-year professional assistant. Only five years later can you take the medical certificate. It is too difficult for a private doctor to obtain the legal status of a general practitioner. If there is no legal private doctor to serve in the primary medical institutions,just as the source of no water, the basic service capacity will gradually shrink, and the private Chinese medicine practitioners will also bear illegality for a long time. The identity is inherited from the growing ethnic medicine. Not only can we not develop primary medical care for the benefit of ethnic minority areas, but also can not really drive the development of the entire industrial chain.

\subsection{Model of Driving Force of Ethnic Medicine Industry Chain}

As shown in the following figure,this paper believes that the driving force for the development of the national pharmaceutical industry is the national medicine industry. Only address the coverage of ethnic medicine hospitals, 
clinics and clinics on the supply side, through the comprehensive increase of service population,outpatient fees,hospitalization fees, etc. The market demand for ethnic medicine can be increased. The increase in demand can in turn promote the development of the national pharmaceutical industry. The development of the cause is the premise of industrial development, and industrial development can drive the development of ethnic medicine planting industry. Combine industry with poverty alleviation work in emerging areas, and gradually adjust the role of industrial structure in ethnic areas. Many ethnic areas have determined the direction of developing a large health industry based on their resource characteristics, cultural characteristics and national characteristics. The national medicine industry is a comprehensive industrial chain involving the linkage of the first,second and third industries. The development of the industry will drive the research and development of ethnic medicines. The main body of research and development should be enterprises. The government plays a guiding role. Only the spontaneous research impulses of enterprises can create The products and research required by the market,in the process of research and development,are bound to promote the protection and organization of the national medical literature. Through long-term observation,the author finds that the research on the driving force of the national pharmaceutical industry chain is insufficient,which leads to the limited speed and quality of industrial development in these years, and the phenomenon of inversion of the end of the industry appears. It not only pays attention to the literature finishing work at the end of the industrial chain,but also does not know that R\&D and document protection are The inevitable result of good industrial development momentum,if the national medicine industry and industry are developing slowly, then the national medicine research and development and document protection will lose the market power.

\section{REFERENCES}

1. Du Yanyan, Jia Qian, Zhong Hailiang, Kong Xiaoyu n, Zhu Guoben. A Path Analysis of Revitalizing Chi nese Medicine and Ethnic Medicine [j].]2 Chinese Jo urnal of traditional Chinese Medicine 2007

14(11).4-5.

2. Zhou Xingwei. Tibetan Medicine [j].in Tibetan Area, Sichuan Journal of Southwest University for nationa lities: humanities and Social Sciences Edition 2009( 2):164-169.

3. Xu Jun, Li Guifang, Wang Yuhong,. Analysis on the Driving Factors of the Biopharmaceutical Industry to Enhance Core Competitiveness [j].and Modern Man agement Science ,2014(7):52-54.

4. Zhu Genghua, XiongYaokun, Zhong Guoyue. Resear ch on the Predicament and Reform Strategy of the D evelopment of Ethnic Minority Medicine Industry -A Case study of Mongolian, Tibetan and Uygur Med icine $[\mathrm{J}]$. Journal of southwest university for national ities: humanities and social sciences,2015,36(8):147151.

5. Wang Runqiu. Research on the Industrialization of $\mathrm{C}$ hinese Ethnic Medicine [J]. Heilongjiang Nationaliti es Series,2015(5):55-62. 